TP Periodica Polytechnica

Social and Management

Sciences

26(1), pp. 1-9, 2018

https://doi.org/10.3311/PPso.9017

Creative Commons Attribution (i)

RESEARCH ARTICLE

\section{Order Management System Proposal Using Inventory Balance Equation with Non-continuous Replenishment}

\author{
Veronika Novotna $^{1 *}$, Tereza Sustrova ${ }^{1}$
}

Received 13 January 2016; accepted after revision 11 April 2016

\begin{abstract}
The purpose of this paper is to present an inventory balance model including an order-up-to replenishment policy with partial backlogging. Pictured in the model is a situation, where goods are not replenished continuously, but only at predetermined intervals. The model is described by ordinary differential equations with delayed argument because of the assumption of a time lag between ordering and delivery.

A computer simulation which helps to demonstrate and verify model behaviour is utilized for the numerical solution of the model. Sales data of a real company are used as the input data.

Due to the comparison of the designed model outputs against the real state in the company, it was verified that it is possible to achieve a substantial reduction in warehousing costs without a disproportionate increase in the risk of inventory shortage. The authors note that modern methods of functional analysis can be successfully applied in solving an inventory balance model.
\end{abstract}

\section{Keywords}

inventory balance equation, inventory management, delay differential equation, computer simulation

\footnotetext{
${ }^{1}$ Department of Informatics, Faculty of Business and Management, Brno University of Technology, Czech Republic

*Corresponding author, e-mail: novotna@fbm.vutbr.cz
}

\section{Introduction}

Every organization, whether profitable or non-profitable one, manage certain assets. Managing and exploiting these assets for corporate purposes is an inseparable part of managerial work at all levels of management. The most significant component of current assets is inventory, which is typical for its perishability.

The purpose of this paper is to introduce a model of inventory balance equation extended by an order up to replenishment policy with partial backlogging, described by means of an ordinary differential equation with delayed argument in a situation when goods are not replenished constantly, but only at pre-specified times.

The economic theory that forms the essential basis for the model is explained in the introductory section and serves as a basis for the designing of the model. Methods of analysis, synthesis and differential calculus are also used. The equation of the model is then solved using the modern theory of so-called functional differential equations, a highly special part of which is the theory of linear differential equations with delayed arguments.

The scientific aim is a solvability verification of such a problem using the theory of functional differential equations. The solution is demonstrated on a specific example in the application part. Computer simulations help to present the behaviour of the model in different situations. The graphical presentation was created in Maple system.

Our findings are that due to the exact expression of the model and the availability of suitable software, it is possible to assess the effect of any changes in parameters.

\section{Materials and methods}

When considering investments in business economics, it is important to be aware that in many industrial and trading companies stock represents the largest investment. In manufacturing plants and trading companies, stock may account for more than $20 \%$ and more than $50 \%$ of total assets respectively (Lambert et al., 2000). The competitive character of the market in the last twenty years has resulted in, among others, a growth in stock. The main reasons were that on the one hand, companies 
tried hard to meet the needs of the diverse market segments by stocking a considerably extended range of products and on the other hand, customers required immediate satisfaction of their needs and, consequently, higher availability of goods. A rise in stock levels is a logical impact of such requirements. At the same time, a need arose to pay sufficient attention to inventory management, which may lead to both a better cash-flow and to higher return on investment.

Inventory management is an essential part of business operations, especially in retail business. The main reason is that the availability of goods in retail has an immediate impact on buyer experience and, consequently, may significantly influence buyer behaviour. This issue has been investigated in a lot of papers that take into consideration such aspects as information accuracy (Fleisch et al., 2005, Dehoratius et al., 2008), perishability (Blackburn and Scudder, 2009, Maihami and Kamalabadi, 2012), product range (Ketzenberg, 2000) and demand substitution (Smith and Agrawal, 2009; Yücel et al., 2009). Characteristics of Supply Chain Management (Horvat et al., 2015) or logistics were also studied (Grundey and Rimienè, 2007). According to (Elsayed, 2013), inventory represents one of the most important and, at the same time, difficult assets, which should be addressed both on a corporate level and on a macroeconomic level.

Inventory management, as one of the essential parts of management of industrial companies and retail businesses, is presented for instance in the publication (Nenes et al., 2010), which emphasises the impact of inventory on their global performance. The impact of purchasing activity on the cash flow of a company is studied by (Vörösmarty and Dobos, 2013).

Li (2013) seeks to apply the theory of optimal management on the production-inventory problem and analyses a situation when the model even features tradable emissions permits; (Geary et al., 2006) explores issues caused by the instability of a supply chain; while seasonal demand is studied by (Costantino et al., 2013). The impact on creating an inventory management strategy in the event that a supplier allows delays in payments is discussed by authors (Abad and Jaggi, 2003; Jaber and Osman, 2006) or (Yang and Wee, 2006). The bullwhip effect has been analysed from various points of view, e.g. the probability theory (Lee et al., 2000), management theory (Disney et al., 2004), game theory (Dobos and Pintér, 2013), differential equations with delays (Warburton, 2004, Csík et al., 2010), stochastic inventory management (Luong and Phien, 2007; Zarandi et al., 2008; Chou, 2010; Chatfield et al., 2004), and the theory of chaos (Hwarng and Xie, 2008). Other authors, such as (Kim et al., 2008) examine volatility by means of the model's system dynamics.

The situation when the demand for goods stabilizes after a certain time is captured by models with ramp type demand rate. The process of stabilization can easily be observed in newly launched products, as described by e.g. (Hill, 1995). The demand rate for a new product rises from the beginning until it stabilizes and becomes constant (Skouri and Konstantaras, 2009).

Moreover, the lifespan of a product also plays a significant role in constructing the model, as after the expiry the product may be rendered worthless or is damaged, etc. (Goyal et al., 2001; Bakker et al., 2012). Other research areas include, for example, models with partial backlogging investigated by (San José et al., 2005; San José et al., 2006). In their paper (Skouri et al., 2009), the authors expanded on the publication (Deng et al., 2007) by introducing a general ramp type demand rate.

In this paper, we proceed from the model which was introduced in (Warburton, 2004) and (Forrester, 2013).

The model is based on the assumption that businessmen seek to fully meet demand $D(t)$, due to the level of inventory $I(t)$, which also allows for accidental influences. That is why the existing level of stock is maintained at about the required level $I_{p}$. The inventory level is then gradually decreased by meeting demand $D(t)$ and, at the same time, increased by the supplied goods $I(t)$. Equation (1) defines the inventory balance:

$$
\partial I / \partial t=R(t)-D(t)
$$

in compliance with reality, it is necessary to assume that there is a certain time delay between ordering goods and the delivery time. It means that the number of goods replenished at time $t$ equals the size of the order at time $t-\tau$.

$$
R(t)=O(t-\tau)
$$

The publication Warburton (Warburton, 2004) defines the replenishment policy equation, where the size of order is directly proportional to the inventory deficit:

$$
O(t)=\left(I_{p}-I(t)\right) / K \text { for } I(t)<I_{p}
$$

and

$$
O(t)=0 \quad \text { otherwise }
$$

$I_{p}$ represents the required level of inventory. In the event of an unexpected rise in demand, inventory is replenished, but thanks to optional parameter $K(K>0)$, the replenishment can be spread over a longer period of time. Equation (4) adds limitations which can stop inventory from being replenished if its level exceeds the required quantity. This prevents overflow of inventory, which is considered an undesirable phenomenon. (Forrester, 2013)

A mathematical model of such an economic process on interval $[0, T]$ is described as follows:

$$
\begin{gathered}
\frac{d I}{d t}=\left\{\begin{array}{c}
\frac{1}{K}\left(I_{p}-I(t-\Delta)\right)-D(t) \text { for } I(t-\Delta) \leq I_{p} \\
-D(t) \text { for }(t-\Delta)>I_{p},
\end{array}\right. \\
I(t-\Delta)=h(t-\Delta) \text { for } t \in[0, \Delta],
\end{gathered}
$$

where function $h(t)$ describes the behaviour of inventory function for $t \in[-\Delta, 0]$. 


\subsection{Solutions of ordinary differential equations with delays}

In economic fields, experiments are sometimes replaced with theoretical models.

Modelling such phenomena is possible owing to methods based predominantly on mathematical disciplines such as statistics, operational research, linear and dynamic programming, numerical methods, optimizing, etc. (David and Křápek, 2013; Fumi et al., 2013). Dependence on time is most crucial in dynamic models. Systems of dynamic equations are divided into autonomous or non-autonomous ones according to whether or not time is explicitly present on their right sides. One way to aptly depict the dynamism of processes in a model is to describe a dynamic model by means of differential equations. Dynamic models are usually defined by means of ordinary or partial differential equations. In such a case, time must be regarded as a continuous quantity. Thanks to this, we may make use of a sophisticated mathematical apparatus of differential and integral calculus. The result is not an estimate of parameters of a pre-defined function type, but rather a function itself, the shape of which gives evidence of the character of the quantities studied.

In his paper describing the above mentioned model, (Forrester, 2013) explores the impact of time delay if the function describing the state of inventory is influenced by demand for the goods. An integral part of the paper is derivation of an ordinary second-order differential equation with delay described in the model. (Warburton, 2004) also takes advantage of opportunities provided by differential equations with delays. In order to solve a model, he uses exponential approximation of the solution (the Lambert $\mathrm{W}$ function), whose main drawback is the fact that the final characteristic equation is transcendent. As a result of this, the calculation of the solution is affected by errors in root approximation.

Mathematical models in economics, described by differential equations and their systems, have solutions complying with certain conditions, and they model the behaviour of economic characteristics in time $t$. In general, such situations are best described by problems of solvability, attributes and/or, if need be, construction of solutions to non-linear ordinary differential equations,

$$
\begin{gathered}
x_{1}^{\prime}(t)=f_{1}\left(t, x_{1}(t), \ldots, x_{n}(t)\right), \\
\vdots \\
x_{n}^{\prime}(t)=f_{n}\left(t, x_{1}(t), \ldots, x_{n}(t)\right),
\end{gathered}
$$

meeting boundary value conditions

$$
\begin{gathered}
h_{1}\left(x_{1}, \ldots, x_{n}\right)=0, \\
\vdots \\
h_{n}\left(x_{1}, \ldots, x_{n}\right)=0,
\end{gathered}
$$

where function $f_{1}, \ldots, f_{n}$ and functionals $\mathrm{h}_{1}, \ldots, \mathrm{h}_{\mathrm{n}}$ meet legitimate requirements in the theory dealing with such problems. At the same time, requirements related to such functions and functionals determine the attributes of solutions to problems (1), (2) ranging from the "classic" solution (all components are continuous and continuously differentiable functions of an independent variable $t$ ), via the Carathéodory solution dating back to the first half of the $20^{\text {th }}$ century (the solution's components are continuous, but its derivation does not have to exist in the set of „measure zero"), to a generalized solution whose components may only be partially Carathéodory's (studied since the second half of the $21^{\text {st }}$ century).

Mathematical models designed to describe economic phenomena have long used and, to a large extent, still use the „classic" model of problem (7), (8). As new methods of Carathéodory theory of differential equations have developed and as the Carathéodory theory has been generalized by the theory of functional differential equations, new mathematical models have been appearing since the middle of the $20^{\text {th }}$ century discovering real issues of economic relations.

Let us focus now on economically proven and useful special cases of the systems of functional differential equations, i.e. the systems of differential equations with constant delays (more delays and also non-constant delays are possible as well as generally "deviated" arguments)

$$
\begin{gathered}
x_{1}^{\prime}(t)=f_{1}\left(t, x_{1}(t-\Delta), \ldots, x_{n}(t-\Delta)\right), \\
\vdots \\
x_{n}^{\prime}(t)=f_{n}\left(t, x_{1}(t-\Delta), \ldots, x_{n}(t-\Delta)\right),
\end{gathered}
$$

or linear systems of differential equations with constant delays

$$
\begin{gathered}
x_{1}^{\prime}(t)=a_{11}(t) x_{1}(t-\Delta)+\cdots+a_{1 n}(t) x_{n}(t-\Delta)+q_{1}(t), \\
\vdots \\
x_{n}^{\prime}(t)=a_{n 1}(t) x_{1}(t-\Delta)+\cdots+a_{n n}(t) x_{n}(t-\Delta)+q_{n}(t),
\end{gathered}
$$

or systems containing both components of a solution with delay and without delay. As it is essential in this situation to know the solution "before" current time $t$, boundary value conditions of the solution's behaviour must be supplemented with corresponding data concerning the "history“ of the solution for $t \in[0, \Delta]$ for example, in the following way

$$
\begin{gathered}
x_{1}(t)=\varphi_{1}(t), \\
\vdots \\
x_{n}(t)=\varphi_{n}(t),
\end{gathered}
$$

where functions $\varphi_{1}, \ldots, \varphi_{n}$ are continuous on the given interval.

By using constructions of solutions to differential equations and their systems with delays derived in the last few decades, we can successfully avoid drawbacks of methods which were used to solve mathematical models in the above mentioned pioneer 
studies. The method described below is based on the theorem of a fixed point of the operator affiliated to the problem. This method has got a "global" character (a solution is obtained by using the method of gradual approximations on the whole interval simultaneously) and is stable from the numerical point of view.

Many real systems which we mathematically model by means of dynamic systems show difficulties caused by delays of one of the modelled quantities. Current literature (Půža and Sokhadze, 2013; Domoshnitsky et al., 2012; Kiguradze and Půža, 2003) dealing with the solvability of such systems provide a range of results which can be applied to real economic problems. In their studies, authors deal with conditions of the solvability of such problems (existence and unambiguity of solutions), conditions of their correctness (i.e. a small change in the input data corresponds with a small change in the solution at the output), conditions determining non-negativity of solutions, etc.

\subsection{Allowing for safety stock in the model}

Uncertainty concerning inventory management may be caused, for example, by excessive consumption or extended delivery time. The aim of safety stock is to cover gaps in supplies or demand.

Our model takes into consideration not only level $I_{p}$ but also the amount of safety stock $I_{p o j}$. Let us assume that in the event of a drop in stock below the safety stock level, at least some goods will need to be replenished earlier, and the replenishment time for these goods will change. In such a case, two optional parameters $K_{1}$ and $K_{2}\left(K_{1}>0, K_{2}>0\right)$ must be introduced, expressing the speed of replenishment of two parts of stock. If $t \in[0, T]$, the model can be described as follows:

$$
\frac{d I}{d t}=\left\{\begin{array}{c}
\frac{1}{K_{1}}\left(I_{p}-I_{p o j}\right)+\frac{1}{K_{2}}\left(I_{p o j}-I(t-\Delta)\right)-D(t) \\
\text { for } I_{p o j} \leq I(t-\Delta) \\
\frac{1}{K_{1}}\left(I_{p}-I(t-\Delta)\right)-D(t) \\
\text { for } I(t-\Delta) \leq I_{p o j} \leq I_{P} \\
-D(t) \\
\text { for } I(t-\Delta)>I_{p}, \\
I(t-\Delta)=h(t-\Delta) \text { for } t \in[0, \Delta]
\end{array}\right.
$$

Let's have

$$
\begin{gathered}
\chi_{[0, T]}(t)=\left\{\begin{array}{l}
1 \text { for } t \geq 0 \\
0 \text { for } t<0,
\end{array}\right. \\
\chi_{I_{p}}(I)= \begin{cases}1 & \text { for } I<I_{p} \\
0 & \text { for } I \geq I_{p},\end{cases} \\
\chi_{I_{p o j}}(I)= \begin{cases}1 \text { for } I<I_{p o j} \\
0 & \text { for } I \geq I_{p o j}\end{cases}
\end{gathered}
$$

Clearly, it is possible, for $t \in[0, T]$ and using the above listed specification to write Eq. (12) down with condition (13) as follows:

$$
\begin{aligned}
\frac{d I(t)}{d t}= & \chi_{I_{p}}(I(t-\Delta)) \chi_{I_{p o j}}\left(I(t-\Delta) \frac{1}{K_{2}} I_{p o j}\right. \\
& -\chi_{I_{p}}(I(t-\Delta)) \chi_{I_{p o j}}(I(t-\Delta)) \frac{1}{K_{2}} \chi_{[0, T]}(t-\Delta) I(t-\Delta) \\
& +\left(1-\chi_{[0, T]}(t-\Delta)\right) h(t-\Delta) \\
& +\chi_{I_{p}}(I(t-\Delta)) \chi_{I_{p o j}}(I(t-\Delta)) \frac{1}{K_{1}}\left(I_{p}-I_{p o j}\right) \\
+ & \chi_{I_{p}}(I(t-\Delta))\left(1-\chi_{I_{p o j}}(I(t-\Delta))\right) \frac{1}{K_{1}} I_{p} \\
& -\chi_{I_{p}}(I(t-\Delta))\left(1-\chi_{I_{p o j}}(I(t-\Delta))\right) \frac{1}{K_{1}} \chi_{[0, T]}(t-\Delta) \\
& I(t-\Delta)-\chi_{I_{p}}(I(t-\Delta))\left(1-\chi_{I_{p o j}}(I(t-\Delta))\right) \\
& \frac{1}{K_{1}}\left(1-\chi_{[0, T]}(t-\Delta)\right) h(t-\Delta)-D(t) \\
& I(t)=I_{h}(t), t \in[-\Delta, 0] .
\end{aligned}
$$

At the same time, a natural consequence of a continuous connection of a solution $I(t)$ from interval $[0, T]$ to ,historic" function $h(t)(t \in[-\Delta, 0])$ is the initial condition of a solution $I(t)$ of Eq. (12) defined as follows:

$$
I(0)=h(0) \text {. }
$$

It follows, from the nature of the above mentioned model, that $I_{p}>0, I_{p o j}>0, \Delta>0, K>0$ are constants, $D(t)$ and $h(t)$ are continuous functions and, from the above stated construction, it follows that problem (12), (13) is equivalent to problem (17), (18).

If the right side of Eq. (2) is marked $L(I)(t)$, then it can be written down as follows:

$$
\frac{d I(t)}{d t}=L(I)(t)
$$

and, given its construction, it is a linear non-homogeneous differential equation with delay with piecewise constant coefficient and with piecewise continuous non-homogeneity ${ }^{1}$. These requirements fully comply with the above-mentioned general theory of functional differential equation, according to which it is adequate for Eq. (20) to consider coefficients and non-homogeneities which are Lebesgue integrable. The considered functions are piecewise constant and piecewise continuous on

1 We will say that function $f$ is on interval $[0, T]$ piecewise continuous (piecewise continuously differentiable), if there is a finite number of points $0=t_{0}<t_{1}<\cdots t_{k}<t_{k+1}<T$ in such a way that function $f$ is continuous (continuously differentiable) on each interval $\left(t_{i}, t_{i+1}\right)(i=0,1, \ldots, k)$ and, at utmost points of the intervals, function $f\left(f^{\prime}\right)$ has got finite one-sided limits.

Analogically, we can say that function is piecewise constant on interval $[0, T]$ if there is a constant finite number of points $0=t_{0}<t_{1}<\cdots t_{k}<t_{k+1}<T$ in such a way that on each interval $\left(t_{i}, t_{i+1}\right)(i=0,1, \ldots, k)$ function $f$ is constant. 
interval $[0, T]$ and meet the above-mentioned requirements. Therefore, it is possible to apply on Eq. (12) the numerical method of constructing a solution and the method of gradual approximations cited in the bibliography.

Based on the above-stated assumptions, problem (12), (13) has got only one solution and the solution can be found on interval $[0, T]$ as continuous and piecewise continuously differentiable. If functions $D(t)$ and $h(t)$ had additional jump-like discontinuities on interval $[0, T]$, the solution of problem (12), (13) would be continuous, but, at points of continuity, it might not have derivation corresponding to the breakdowns.

Conclusions that follow from the theory in (Kiguradze and Půža, 2003; Bobalová and Maňásek, 2007) and from literature dealing with general linear boundary value problems for functional differential equations are the following:

- unequivocal solvability of problem (12), (13) and (17) (18) respectively

- possible construction of a solution via gradual approximations.

Application of the method presented in studies (Kiguradze and Půža, 2003; Bobalová and Maňásek, 2007), allows us to construct a solution to problem (17), (18) using the method of gradual approximations in the following manner:

1. we randomly choose function $I_{0}$ continuous on interval $[0, T]$, for example

$$
I_{0}(t)=h(0), t \in[0, T]
$$

2. we gradually calculate the $n t h$ approximation of the soughtafter solution, $n \in N$, while using auxiliary problem

$$
\frac{d I_{n}(t)}{d t}=L\left(I_{n-1}\right)(t)
$$

$$
\begin{aligned}
\frac{d I_{n}(t)}{d t}= & \chi_{I_{p}}\left(I_{n-1}(t-\Delta)\right) \chi_{I_{p o j}}\left(I_{n-1}(t-\Delta)\right) \frac{1}{K_{2}} I_{p o j} \\
& -\chi_{I_{p}}\left(I_{n-1}(t-\Delta)\right) \chi_{I_{p o j}}\left(I_{n-1}(t-\Delta)\right) \\
& \frac{1}{K_{2}} \chi_{[0, T]}(t-\Delta) I_{n-1}(t-\Delta) \\
& \frac{1}{K_{2}} \chi_{[0, T]}(t-\Delta) I_{n-1}(t-\Delta) \\
& +\left(1-\chi_{[0, T]}(t-\Delta)\right) h(t-\Delta) \\
& +\chi_{I_{p}}\left(I_{n-1}(t-\Delta)\right) \chi_{I_{p o j}}\left(I_{n-1}(t-\Delta)\right) \frac{1}{K_{1}}\left(I_{p}-I_{p o j}\right) \\
& \chi_{I_{p}}\left(I_{n-1}(t-\Delta)\right)\left(1-\chi_{I_{p o j}}\left(I_{n-1}(t-\Delta)\right)\right) \frac{1}{K_{1}} I_{p} \\
& -\chi_{I_{p}}\left(I_{n-1}(t-\Delta)\right)\left(1-\chi_{I_{p o j}}\left(I_{n-1}(t-\Delta)\right)\right) \\
& \chi_{I_{p}}\left(I_{n-1}(t-\Delta)\right)\left(1-\chi_{I_{p o j}}\left(I_{n-1}(t-\Delta)\right)\right) \\
& \frac{1}{K_{1}}\left(1-\chi_{[0, T]}(t-\Delta)\right) h(t-\Delta)-D(t),
\end{aligned}
$$

$$
I_{n}(0)=h(0)
$$

\section{Model of piecewise continuous supply of goods}

The model only gives a partly true picture of a real situation that may be encountered in inventory management. If we want to make the situation as real as possible, we need to take account of the fact that goods are not replenished continuously, nor do they have to be replenished in regular intervals. Therefore, it is necessary to moderately modify the model and to take into consideration that replenishment only takes place in certain subintervals of interval $[0, T]$.

Let us establish $T_{s}$ set of all subintervals from $[0, T]$, when goods are replenished. The adjusted model can be written down by means of relationship (20) as follows:

$$
\begin{aligned}
& \frac{d I(t)}{d t}=\left\{\begin{array}{l}
L(I)(t) t \in T_{s} \\
-D(t) t \notin T_{s}
\end{array} .\right. \\
& I(0)=h(0) .
\end{aligned}
$$

If, analogically with previous thoughts, we determine a characteristic function of set $T_{s}$

$$
\chi_{T_{s}}(t)=\left\{\begin{array}{ll}
1 & t \in T_{s} \\
0 & t \notin T_{s}
\end{array} .\right.
$$

We may write down the above mentioned problem as follows:

$$
\begin{aligned}
\frac{d I(t)}{d t} & =\chi_{T_{s}}(t) L(I)(t)-\left(1-\chi_{T_{s}}(t)\right) D(t), \\
I(0) & =h(0) .
\end{aligned}
$$

Solution $I(t)$ of this equation can be obtained by using the method of gradual approximations as $\lim _{n \rightarrow \infty} I_{n}(t)$, where for each $n \in N$

$$
\begin{gathered}
\frac{d I_{n}(t)}{d t}=\chi_{T_{s}}(t) L\left(I_{n-1}\right)(t)-\left(1-\chi_{T_{s}}(t)\right) D(t), \\
t \in[0, T], \\
I(0)=h(0) .
\end{gathered}
$$

It must be emphasised that the model, which describes the economic process of inventory management in a more realistic way, is again an initial problem for a linear differential equation with constant delay $\Delta$, piecewise constant coefficients, piecewise continuous non-homogeneity.

Therefore, its solution will be a continuous function and, in some parts continuously differentiable on interval $[0, T]$, or, in other words, a continuous function on $[0, T]$, with the utmost number of points lying within the interval, at which there is no derivation. The graph of such a solution is a continuous function on $[0, T]$ with the utmost definite number of "steps".

\section{Data}

The proposed model of solution of the inventory balance equation is applied to real situations from business. The data were provided by an existing company, a wholesale dealer with 
connecting materials. Being part of a supply chain, the company buys from an Asian supplier and has to allow for a replenishment lead time of up to 60 days from the date of order. The order interval is approximately one month, i.e. 20 working days, and the average size of an order is 800 units. The company requires optimization of the costs of goods by reducing the interval between orders and by lowering the amount of ordered goods, which should result in a drop in warehousing costs.

An initial sales analysis was carried out based on the data concerning sales of one of its fast moving consumer products between January 2009 and December 2014; the demand curve is shown in Fig. 1. Prediction of sales, done by means of neuron networks (Varyšová, 2015) in the following two months, (January and February 2015) was converted to daily demand. Results of this analysis will be used for further calculations.

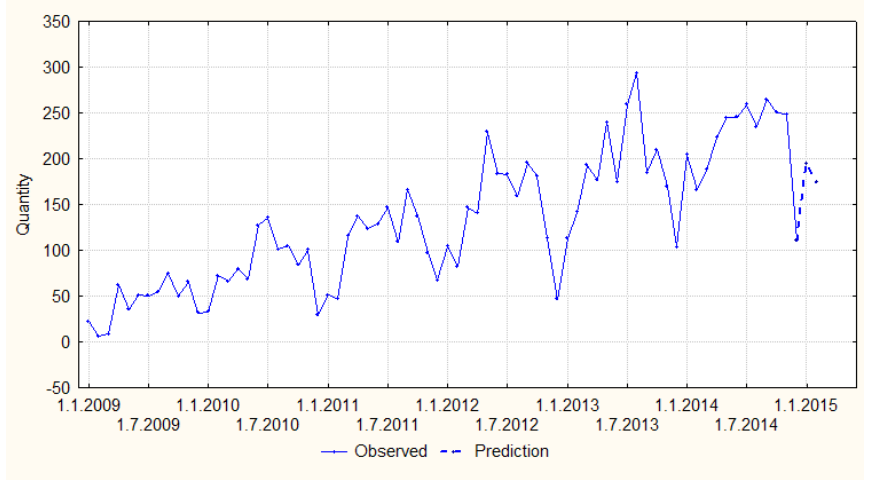

Fig. 1 Monthly sales from January 2009 to December 2014 with predicted sales for January and February 2015

\subsection{Utilized Software}

Maple is a computer algebra system designed to teach mathematics and apply it in natural, technical and economic sciences. Its origins date back to the 1990 s and its $15^{\text {th }}$ version is now available. Maple was created with the aim of simplifying and accelerating mathematical computations. Maple can be used not only for basic mathematical computations, but also in mathematical analysis, in linear algebra, in mathematical logic, etc. Maple makes both symbolic and numerical calculations and is used to make graphs, special documents, presentations and interactive computational modules. Besides that, it can also create graphs of functions - one or two variables. Another advantage is that data can be stored in diverse formats and can be exported to other programming languages.

\section{Results and Discussion}

\subsection{Initial Assumptions}

A delay of the model is derived from the delivery time of 60 days. The level of inventory at which goods are ordered is set up by the company management at 700 units, and the level of safety stock is 200 units.
The historic function arises from the specific development of inventory level in the previous 60 working days, which allows us to monitor the development of inventory with a 3-month delay. Parameters $\mathrm{K}_{1}$ and $\mathrm{K}_{2}$ have been set at 2.3 and 1.5 respectively.

After the company management of the company had been consulted, the interval between deliveries was reduced to 7 days, while the size of the order will not be fixed, but it will be derived from the current state of the warehouse.

\subsection{Input data}

$$
\begin{aligned}
& \Delta=60 ; K_{2}=1.5 ; K_{1}=2.3 ; I_{p}=700 ; I_{p o j}=200 \\
& D(t)=\left\{\begin{array}{l}
11.14 \text { for } t \in\langle 0 ; 9) \\
13 \text { for } t \in\langle 9 ; 28) \\
12 \text { for } t \in\langle 28 ; 49) \\
15.7 \text { for } t \in\langle 49 ; 60) \\
12 \text { for } t \in\langle 60 ; \infty) .
\end{array}\right. \\
& I_{h}(t)=\left\{\begin{array}{l}
-304-13.2 t \text { for } t \in\langle-60 ; 52) \\
400-11.3 t \text { for } t \in\langle-52 ;-38) \\
349-12.7 t \text { for } t \in\langle-38 ;-16) \\
370-11.8 t \text { for } t \in\langle-16 ; 0) .
\end{array}\right.
\end{aligned}
$$

Demand $D(t)$ and history function $I_{h}(t)$ is given according to the actual development in the company. A calculated solution of the model as per the given parameters is shown in the following graph (Fig. 2).

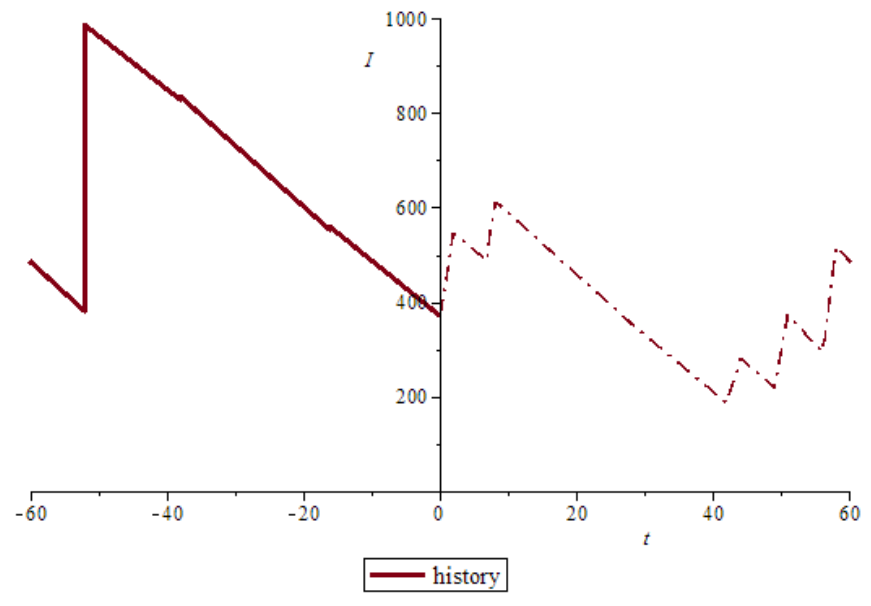

Fig. 2 Inventory movement as per the model's solution

In the following text we would like to outline the model behaviour in the case of a change of selected parameters.

\subsection{The impact of changes in parameter $K_{1}$}

An increase in the value of parameter $K_{1}$ means extension of replenishment time, i.e. bringing the inventory to the required level $I_{p}$. If we consider $K_{1}=3$ (while keeping all the other parameters at the original level) the behaviour of the model changes as follows - see Fig. 3. 


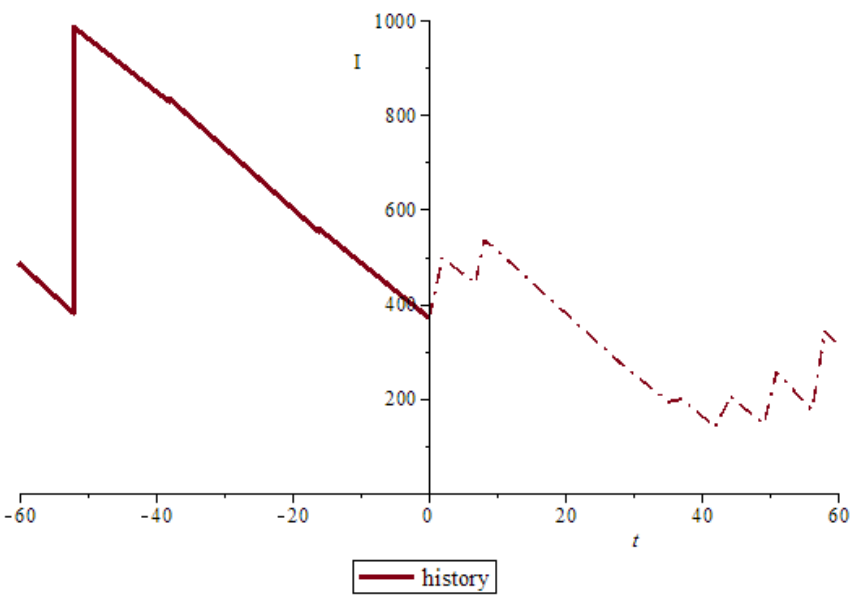

Fig. 3 A change of the model with increased parameter K1

As we can see from the figure, inventory in $t \in(37 ; 50)$ is kept below the level of safety stock, which is not the optimal solution. In this case, the company would have to face the danger of inventory shortages in case of unexpectedly large orders.

\subsection{Comparison with the real situation}

Thanks to the known situation in the company, we can compare the results of the proposed model with real development of the inventory level in the company. The inventory level of the proposed model compared with the level of real inventory kept in the company is shown in Fig. 4.

From the graph it can be seen that proposed model allows us to optimize the inventory level in a given period. Unlike actual development in the company where an inadequately large stock level over a long time period can be observed, the proposed model enabling regular deliveries maintains the stock at a lower level and thus reduces storage costs.

The proposed model thus enables a considerable economy of warehousing costs. The curve of the warehousing costs is demonstrated in the following graph (Fig. 5).

The "Proposed model" line shows the curve of accumulated daily warehousing costs based on the proposed model.

The "Real inventory" line shows the curve of daily warehousing costs while keeping the existing order system.

It can be seen in the graph that thanks to the model the amount of warehousing costs decreases almost by $50 \%$ in the given period. Total warehousing costs of in the real situation are 2834 monetary units and in the proposed model are 1511 monetary units.

\subsection{Prediction of the future}

It has been verified that the model proposes more efficient purchasing policy for the company based on real data. Therefore, it is appropriate to propose a suitable ordering policy for the next period. A model suggesting stock level for the next period based on the demand prediction using artificial neural networks is proposed.

$$
\begin{aligned}
& \Delta=60 ; K_{2}=1.6 ; K_{1}=1.14 ; I_{p}=700 ; I_{p o j}=200 \\
& D(t)=\left\{\begin{array}{c}
9 \text { for } t \in\langle 0 ; 7) \\
6 \text { for } t \in\langle 7 ; 20) \\
10 \text { for } t \in\langle 20 ; \infty)
\end{array}\right. \\
& I_{h}(t)=\left\{\begin{array}{l}
-384-12 t \text { for } t \in\langle-102 ;-56) \\
380-12.78 t \text { for } t \in\langle-56 ; 0) .
\end{array}\right.
\end{aligned}
$$

Demand values $D(t)$ were determined according to the prediction using artificial neural networks; history function $I_{h}(t)$ is given according to the actual development. Predicted demand acquires dramatically lower values than demand in situations with real data and for this reason a different value of parameter $K_{1}$ and $K_{2}$ is determined. A calculated solution of the model as per the given parameters is shown in the following graph (Fig. 6).
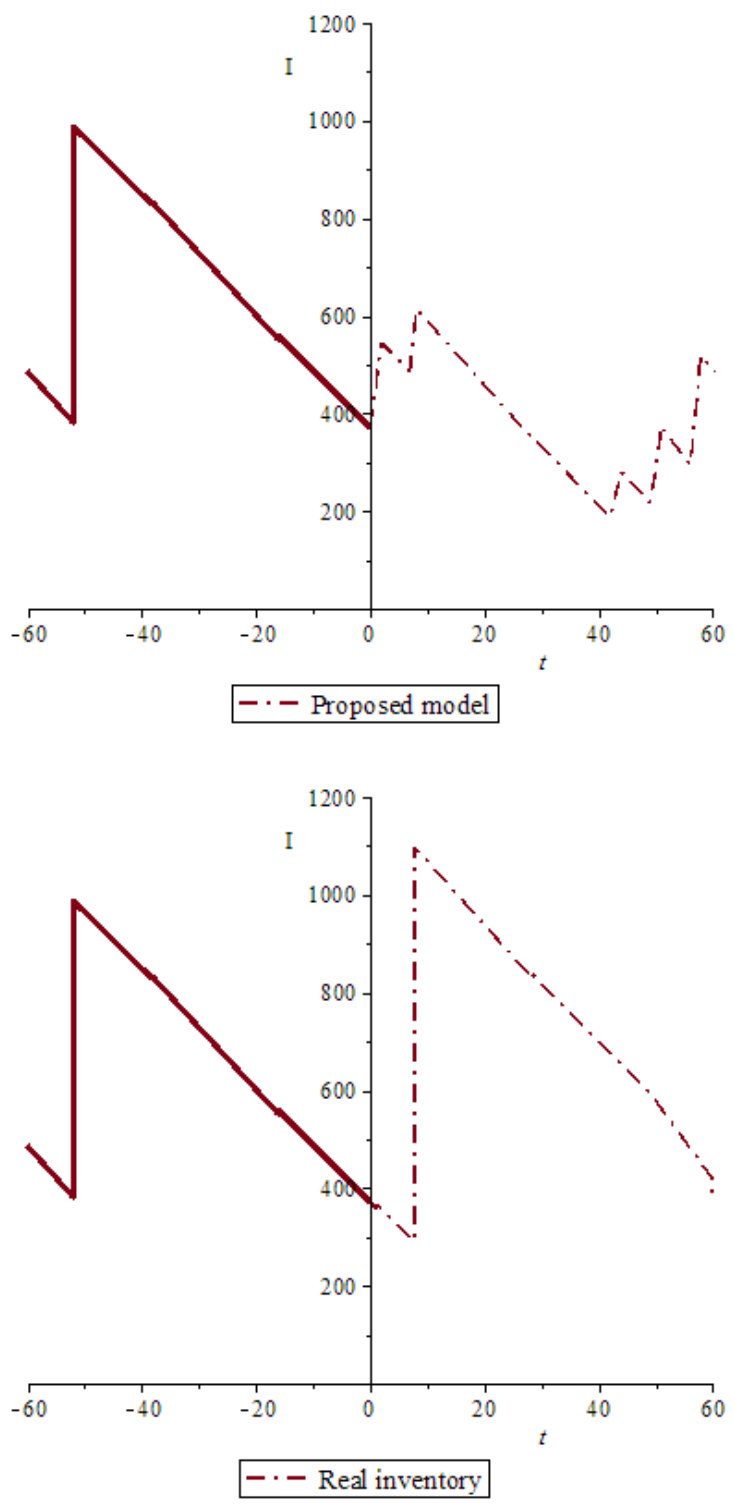

Fig. 4 Comparison of inventory level according to proposed model and real situation 


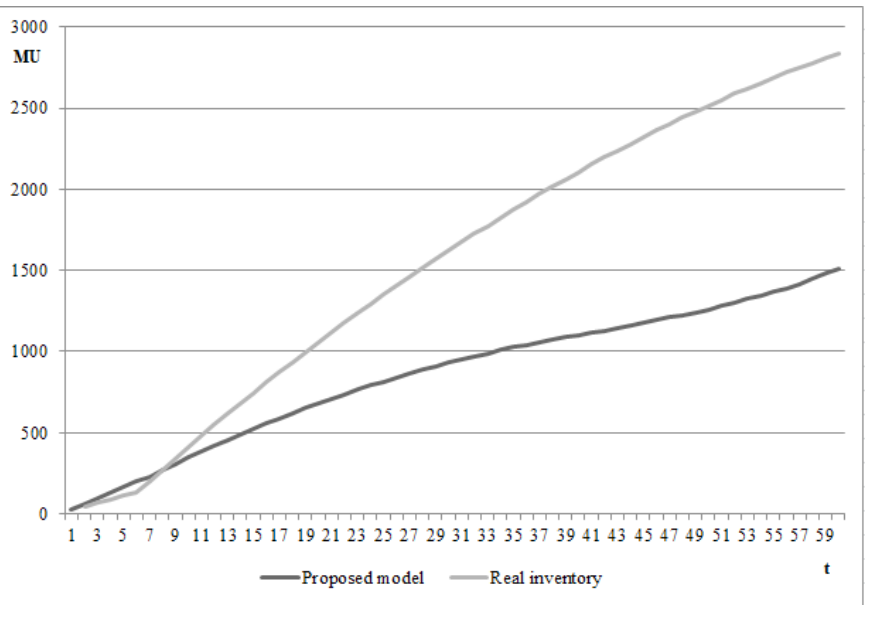

Fig. 5 Comparison of accumulated warehousing costs

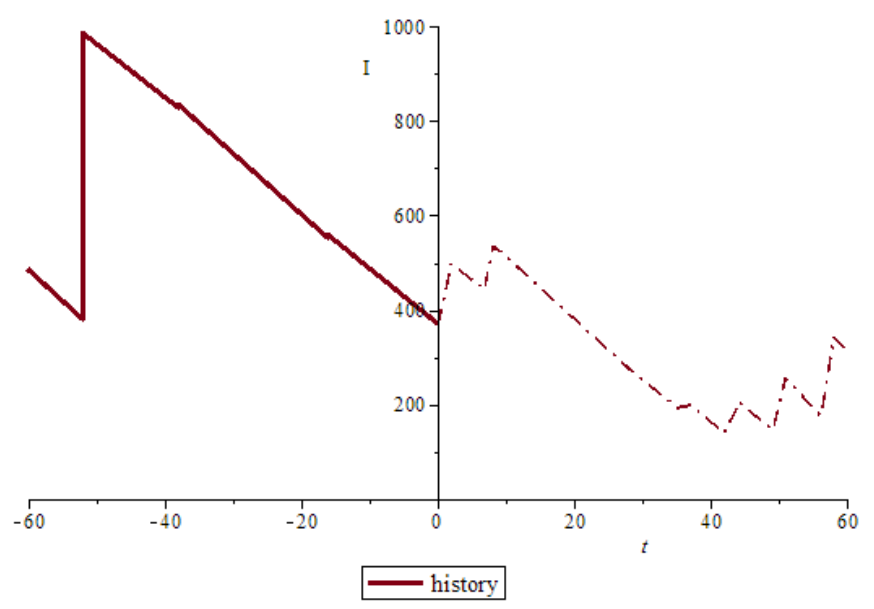

Fig. 6 Inventory movement as per the model's solution with predicted demand

\section{Conclusion}

A very important role in the company management, of trade or production, is played by proper inventory management. The company thus gains the ability to keep inventory level sufficient for continuous supply, production and sale while achieving minimal costs associated with the warehousing of goods. The paper introduced a model of inventory balance equation extended by an orderupto replenishment policy with partial backlogging, described by means of an ordinary differential equation with delayed argument.

The model presented in the paper does describe a real situation which may arise in inventory management and among other things it allows solving a situation where stock is emptied continuously, but goods are replenished in steps at irregular intervals.

Computer simulations help to demonstrate the model's behaviour while using real data. The example based on actual data provided by a company confirms that using methods of modern functional analysis can successfully solve such a problem. Thanks to this the proposed model is able to reduce the risk of supplies shortages on the one hand and to significantly reduce the need of both financial means and warehousing costs on the other.

The model analysed in this paper may be extended in the future. One option is to consider generalization of the model, which would allow us to work with non-constant delay, thus bringing the model even closer to reality.

\section{Acknowledgement}

This paper was supported by grant FP-S-15-2787 "Effective Use of ICT and Quantitative Methods for Business Processes Optimization" from the Internal Grant Agency at Brno University of Technology.

\section{References}

Abad, P. L., Jaggi, C. K. (2003). A joint approach for setting unit price and the length of the credit period for a seller when end demand is price sensitive. International Journal of Production Economics. 83(2), pp. 115-122. https://doi.org/10.1016/s0925-5273(02)00142-1

Bakker, M., Riezebos, J., Teunter, R. H. (2012). Review of inventory systems with deterioration since 2001. European Journal of Operational Research. 221(2), pp. 275-284. https://doi.org/10.1016/j.ejor.2012.03.004

Blackburn, J., Scudder, G. (2009). Supply Chain Strategies for Perishable Products: The Case of Fresh Produce. Production and Operations Management. 18(2), pp. 129-137. https://doi.org/10.1111/j.1937-5956.2009.01016.x

Bobalová, M., Maňásek, L. (2007). On Constructing a Solution of a Multipoint Boundary Value Problem. In: CDDE 2006: Colloquium on differential and difference equations. Brno, Sept. 5-8, 2006. pp. 93-100.

Chatfield, D. C., Kim, J. G., Harrison, T. P., Hayya, J. C. (2004). The Bullwhip Effect-Impact of Stochastic Lead Time, Information Quality, and Information Sharing: A Simulation Study. Production and Operations Management. 13(4), pp. 340-353. https://doi.org/10.1111/j.1937-5956.2004.tb00222.x

Chou, C. C. (2010). A New Fuzzy Backorder Inventory Model for the Decision Making of Material Inventory in the Manufacture System. Key Engineering Materials. 12(5), pp. 106-109. https://doi.org/10.4028/www.scientific.net/kem.431-432.106

Csík, A. G. T., Horváth, T. L., Földesi, P. (2010). An Approximate Analytic Solution of the Inventory Balance Delay Differential Equation. Acta Technica Jaurinensis. 3(3), pp. 231-256.

Costantino, F., Di, G., Shaban, A., Tronci, M. (2013). Exploring the Bullwhip Effect and Inventory Stability in a Seasonal Supply Chain. International Journal of Engineering Business Management. (5). https://doi.org/10.5772/56833

David, P., Křápek, M. (2013). Older motor vehicles and other aspects within the proposal of environmental tax in the Czech Republic. Acta Universitatis Agriculturae et Silviculturae Mendelianae Brunensis. 61(7), pp. 2033-2043.

Dehoratius, N., Mersereau, A. J., Schrage, L. (2008). Retail Inventory Management When Records Are Inaccurate. Manufacturing. 10(2), pp. $257-$ 277. https://doi.org/10.1287/msom.1070.0203

Deng, P. S., H. J. Lin, R., Chu, P. (2007). A note on the inventory models for deteriorating items with ramp type demand rate. European Journal of Operational Research. 178(1), pp. 112-120. https://doi.org/10.1016/j.ejor.2006.01.028 
Disney, S. M., Towill, D. R. \& van de Velde, W. (2004). Variance amplification and the golden ratio in production and inventory control. International Journal of Production Economics. 90(3), pp. 295-309. https://doi.org/10.1016/j.ijpe.2003.10.009

Dobos, I., Pintér, M. (2013). Cooperation in an HMMS-type supply chain: A management application of cooperative game theory. Periodica Polytechnica Social and Management Sciences. (21)1, pp. 45-52. https://doi.org/10.3311/PPso.2156

Domoshnitsky, A., Hakl, R., Půža, B. (2012). On the dimension of the solution set to the homogeneous linear functional differential equation of the first order. Czechoslovak Mathematical Journal. 62(4), pp. 1033-1053. https://doi.org/10.1007/s10587-012-0062-1

Elsayed, K., Wahba, H. (2013). Reinvestigating the relationship between ownership structure and inventory management: A corporate governance perspective. International Journal of Production Economics. 143(1), pp. 207-218. https://doi.org/10.1016/j.ijpe.2013.01.011

Fleisch, E., Tellkamp, Ch., Chen, L., Mersereau, A. J. (2005). Inventory inaccuracy and supply chain performance: a simulation study of a retail supply chain. International Journal of Production Economics. 95(3), pp. 79-112. https://doi.org/10.1007/978-1-4899-7562-1_5

Forrester, J. W. (2013). Industrial Dynamics. 2nd edition, Martino Fine Books, Cambridge.

Fumi, A., Pepe, A., Scarabotti, L., Schiraldi, M. M. (2013). Fourier analysis for demand forecasting in fashion company. International Journal of Engineering Business Management. 5(30), pp. 1-10.

Geary, S., Disney, S. M., Towill D. R., Campuzano, F., Mula, J. (2006). On bullwhip in supply chains-historical review, present practice and expected future impact. International Journal of Production Economics. 101(1), pp. 23-35. https://doi.org/10.1007/978-0-85729-719-8_3

Goyal, S. K., Giri, B. C., Kuijsten, A., Harris, D. P., Liu, P. L. F., Amoudry, L. O. (2001). Recent trends in modeling of deteriorating inventory: An Overview. European Journal of Operational Research. 134(1), pp. 23-28. https://doi.org/10.1007/978-3-540-75995-9_5

Grundey, D., Rimienè, K. (2007). Logistics centre concept through evolution and definition. Engineering Economics. 4(54), pp. 87-95.

Hill, R. M. (1995). Inventory Models for Increasing Demand Followed by Level Demand. Journal of the Operational Research Society. 46(10), pp. 1250-1259. https://doi.org/10.1057/jors.1995.172

Hwarng, H. B., Xie, N. (2008). Understanding supply chain dynamics: A chaos perspective. European Journal of Operational Research. 184(3), pp. 1163-1178. https://doi.org/10.1016/j.ejor.2006.12.014

Horvat, A., Antic, S., Jeremic, V. (2015). A New Perspective on Quality Characteristics Determining Supply Chain Management of Coffee Production. Engineering Economics. 26(3), pp. 239-244.

Jaber, M. Y., Osman, I. H. (2006). Coordinating a two-level supply chain with delay in payments and profit sharing. Computers. 50(4), pp. 385-400. https://doi.org/10.1016/j.cie.2005.08.004

Ketzenberg, M. (2000). Inventory policy for dense retail outlets. Journal of Operations Management. 18(3), pp. 303-316. https://doi.org/10.1016/s0272-6963(99)00033-9

Kiguradze, I., Půža, B. (2003). Boundary value problems for systems of linear functional differential equations. Masaryk University, Brno.

Kim, I., Springer, M., Rodriguez, W., Zalewski, J., Kirche, E. (2008). Measuring endogenous supply chain volatility: Beyond the bullwhip effect. European Journal of Operational Research. 189(1), pp. 172-193. https://doi.org/10.4018/9781599045887.ch009

Lambert, D., Stock, J. R., Ellram, L. (2000). Logistika. (Logistics.) 1st edition, Computer Press, Praha. (in Czech)

Lee, H. L., So, K. C., Tang, Ch. S. (2000). The Value of Information Sharing in a Two-Level Supply Chain. Management Science. 46(5), pp. 626-643. https://doi.org/10.1287/mnsc.46.5.626.12047
Li, S. (2013). Optimal control of the production-inventory system with deteriorating items and tradable emission permits. International Journal of Systems Science. 45(11), pp. 2390-2401. https://doi.org/10.1080/00207721.2013.770103

Luong, H. T., Phien, N. H. (2007). Measure of bullwhip effect in supply chains: The case of high order autoregressive demand process. European Journal of Operational Research, 183(1), pp. 197-209.

Maihami, R., Kamalabadi, I. N. (2012). Joint pricing and inventory control for non-instantaneous deteriorating items with partial backlogging and time and price dependent demand. International Journal of Production Economics. 136(1), pp. 116-122. https://doi.org/10.1016/j.ijpe.2011.09.020

Nenes, G., Panagiotidou, S., Tagaras, G. (2010). Inventory management of multiple items with irregular demand: A case study. European Journal of Operational Research. 205(2), pp. 313-324. https://doi.org/10.1016/j.ejor.2009.12.022

Půža, B. \& Sokhadze, Z. (2013). Weighted Cauchy problem for nonlinear singular differential equations with deviating arguments. Differential Equations. 49(1), pp. 295-302. https://doi.org/10.1016/b978-0-08-034357-0.50039-0

San José, L. A., Sicilia, J., García-Laguna, J. (2005). The lot size-reorder level inventory system with customers impatience functions. Computers \& Industrial Engineering. 49(3), pp. 349-362.

San José, L. A., Sicilia, J., García-Laguna, J. (2006). Analysis of an inventory system with exponential partial backordering. International Journal of Production Economics. 100(1), pp. 76-86.

Skouri, K., Konstantaras, I. (2009). Order Level Inventory Models for Deteriorating Seasonable/Fashionable Products with Time Dependent Demand and Shortages. Mathematical Problems in Engineering. 2009(1), pp. 1-24. https://doi.org/10.1155/2009/679736

Skouri, K., Konstantaras, I., Papachristos, S. \& Ganas, I. (2009). Inventory models with ramp type demand rate, partial backlogging and Weibull deterioration rate. European Journal of Operational Research. 192(1), pp. 79-92. https://doi.org/10.1016/j.ejor.2007.09.003

Smith, S. A., Agrawal, N. (2000). Management of Multi-Item Retail Inventory Systems with Demand Substitution. Operations Research. 48(1), pp. 319-347. https://doi.org/10.1007/978-1-4899-7562-1_12

Varyšová, T. (2015). Time Series Forecasting Using Artificial Neural Network. In: Proceedings of the 25th International Business Information Management Association Conference. International Business Information Management Association (IBIMA), Amsterdam, pp. 527-535.

Vörösmarty, G., Dobos, I. (2013). Analysis of purchasing activity with discounted cash flow inventory models. Periodica Polytechnica Social and Management Sciences. 21(2), pp. 67-70. https://doi.org/10.3311/PPso.7085

Warburton, R. D. H. (2004). An Analytical Investigation of the Bullwhip Effect. Production and Operations Management. 13(2), pp. 150-160. https://doi.org/10.1111/j.1937-5956.2004.tb00151.x

Yang, P. C., Wee, H. M., Wee, K. P. (2006). An integrated vendor-buyer inventory model with perfect and monopolistic competitions: an educational note. International Transactions in Operational Research. 13(1), pp. 7583. https://doi.org/10.1111/j.1475-3995.2006.00534.x

Yücel, E., Karaesmen, F., Salman, F. S., Türkay, M. (2009). Optimizing product assortment under customer-driven demand substitution. European Journal of Operational Research. 199(3), pp. 759-768.

Zarandi, M. H. F., Pourakbar, M., Turksen, I. B. (2008). A Fuzzy agent-based model for reduction of bullwhip effect in supply chain systems. Expert Systems with Applications. 34(3), pp. 1680-1691. https://doi.org/10.1016/j.eswa.2007.01.031 